\title{
The Strategy of Hospital Wastewater Treatment to Reduce the Risk of Virus Transmission and Environmental Pollution under COVID-19 based on Big Data
}

\author{
Qianhui Huang ${ }^{1, a, *, \dagger}$, Peilin $\mathrm{Liu}^{2, \mathrm{~b},{ }^{*}, \dagger}$, Jiangwei Xie ${ }^{3, \mathrm{cc}, *, \dagger}$ \\ ${ }^{1}$ South China University of Technology, Guangzhou 510006, China. \\ ${ }^{2}$ Nanjing Agricultural University, Nanjing 210014, China. \\ ${ }^{3}$ Guangdong University of Technology, Guangzhou 510006, China. \\ ${ }^{*}$ Corresponding author's e-mail: \\ $†$ These authors contributed equally.
}

\begin{abstract}
The novel coronavirus (COVID-19) is sweeping the world starting in 2019. According to the analysis based on big data technology, the wastewater generated by hospitals hosting SARS-CoV-2 infected patients is complex in origin and composition, and contains a large number of pathogenic microorganisms and drugs, etc. Without effective treatment, it will become an important pathway for the spread of the epidemic and a source of environmental pollution, so wastewater treatment processes more effective for degrading organic matter and inactivating viruses are required. This paper investigates the improvement measures adopted for hospital wastewater treatment systems in response to COVID-19. For instance, reinforced septic tanks and fine grilles with smaller grids were used for wastewater treatment. Besides, the Moving-bed Biofilm Reactor (MBBR) process and the flocculation slant plate process were widely used for biochemical treatment and sedimentation processes. It is critical to increase the dosage of disinfectant since coronaviruses can be transmitted through water bodies and pose a threat to the environment and human health. Finally, a hightemperature anaerobic digestion and incineration disposal scheme can effectively inactivate sludge pathogenic bacteria and viruses for sludge generated from hospital wastewater treatment. In addition, we propose recommendations for the shortcomings and risks in this treatment system, which are important for improving the efficiency of medical wastewater containing the SARS-CoV-2 virus and stopping further virus transmission.
\end{abstract}

\section{Introduction}

Since the end of 2019, SARS-CoV-2, a new pneumoniacausing virus, has swept the world and rapidly spread to more than 200 countries. The total number of infected people worldwide has reached nearly 200 million, posing a huge threat to human health. Therefore, there have been a series of public health emergencies around the world. SARS-CoV-2 is an enveloped plus stranded RNA virus belonging to the beta coronavirus genus that causes COVID-19 [1]. The main transmission routes are direct contact and respiratory droplets [1], while aerosol or fecal transmission is also proven possible [2].

Countries began to build shelter hospitals to separate SARS-CoV-2 patients from healthy people, target them for treatment, and relieve the strain on the health system caused by many COVID-19 patients. A large number of COVID-19 patients were treated in the shelter hospital, which generated a large amount of medical wastewater during its operation. With big data, SARS-CoV-2 will survive in a water environment and transmit an

201864800342@mail.scut.edu.cn,

b9181310609@njau.edu.cn,

cxie0302@mail2.gdut.edu.cn. incontrovertible fact Fig. 1 [3]. Since SARS-CoV-2 can maintain biological activity in the water, medical wastewater may also be the transmission medium of the virus. Wastewater treatment facilities are usually connected to the air. If the wastewater is not thoroughly treated to kill the virus, the virus may spread from the wastewater to the external environment and expand the number of infected people. Therefore, it is very important to adopt more targeted sewage treatment technology to eliminate the virus and improve sewage treatment. However, few studies on the treatment process of medical wastewater contain the SARS-CoV-2 virus, so it is difficult to systematically analyze the role of each treatment facility in the treatment of this wastewater.

Based on the medical wastewater treatment process of Huoshenshan Hospital, this paper systematically analyzes the most appropriate process that each component facility can adopt under the background of the COVID-19 outbreak and the unique role of each process. After research, this process still has shortcomings. We propose suggestions to improve these problems, which are of great significance for improving the treatment efficiency of 
medical wastewater containing the SARS-CoV-2 virus, ensuring the safety of medical staff and other staff, and

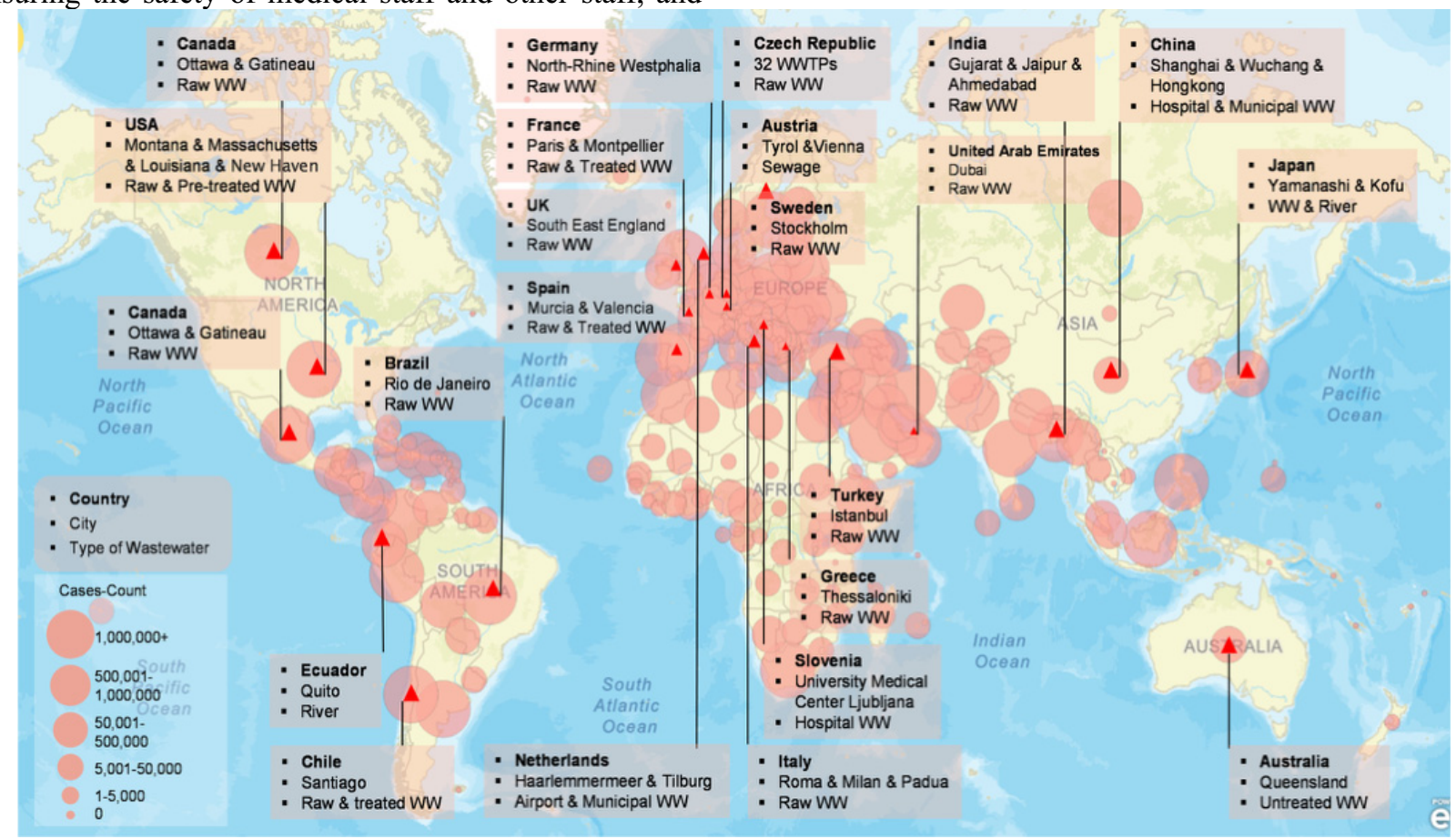

Fig. 1. Confirmed cases of SARS-CoV-2 detection in global aqueous environment [3].

\section{Treatment technology}

\subsection{Processing flow chart}

Huoshenshan Hospital in Wuhan, China, was established during the COVID-19 epidemic and is a hospital specially designed to treat COVID-19 patients. Hospital wastewater contains a large amount of human excrement [4], preventing the further spread of the virus.

containing various inorganic and organic substances such as undigested carbohydrates, fibers, proteins, fats [5]. Therefore, in the process of wastewater treatment, attention should be paid to the removal of viruses.

To better treat medical wastewater, its treatment facilities should be composed of a septic tank, grille, regulating reservoir, biochemical tank, clarifier, disinfection pool, and perfect sludge disposal facilities. That ensures all kinds of waste can be the perfect treatment. The specific processing flow chart is shown in Fig. 2 [6].

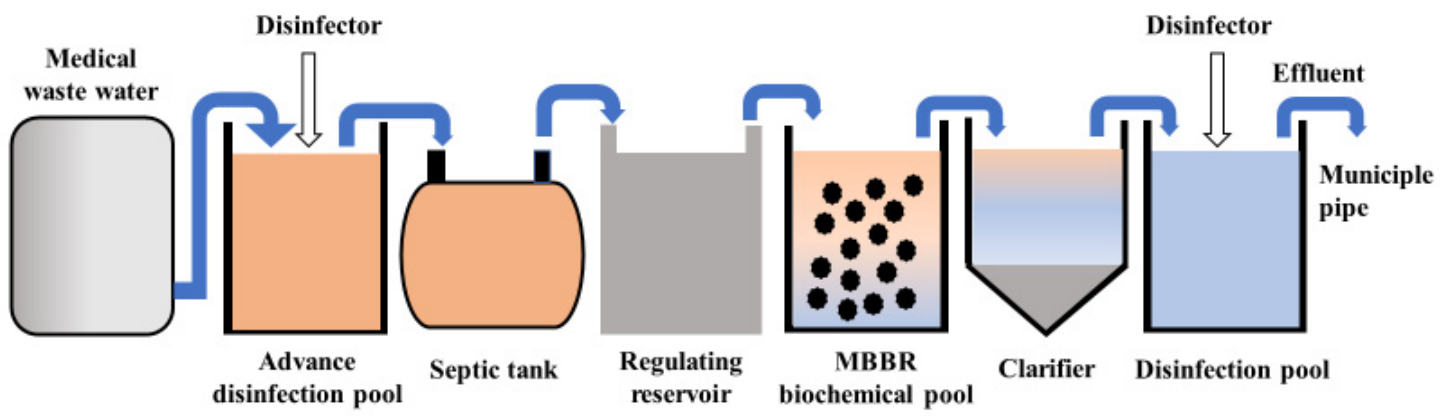

Fig. 2. Flowchart of treatment of medical wastewater containing Novel Coronavirus [6].

\subsection{Septic tank}

Septic tank is a kind of domestic sewage pretreatment facility, using the principle of static separation and anaerobic fermentation. When entering the septic tank, some large particles settle to the bottom of the septic tank to form sludge for anaerobic fermentation. The other suspended particles enter the next stage of sewage treatment facilities and the water flow. However, the sewage treatment efficiency of traditional septic tanks is very low, which will lead to an increase in soil and groundwater pollution [7]. Therefore, it is of great significance to improve the process of the septic tank.

Currently, there are four types of intensified septic tanks, including biogas septic tanks, Up-flow Anaerobic Bed (UASB) septic tanks, packed septic tanks, and baffletype septic tanks. Among them, the characteristics of a 
biogas septic tank are to provide an anaerobic environment for the fermentation of sewage, which is conducive to preventing mosquito breeding, and the methane produced can also be used as energy for the operation of the facility. UASB type septic tank is equipped with a gas/liquid/solid three-phase separation device, which helps to improve the removal rate of suspended particulate matter and the conversion rate of soluble organic matter [8]. Packing type septic tank uses the biofilm attached to the filler to filter and decompose the pollutants in the water. The baffle type septic tank divides the septic tank into several small chambers by using the baffle plate. It has the advantages of completing the separation of the process of acid production and methane production [9], resistance to the change of water pressure, and better residence time of sewage and sludge [10]. As a facility for treating medical wastewater from New Coronet, septic tanks should also pay attention to the use of pre-disinfection and strengthening sealing measures to prevent virus spiltration based on improving sewage treatment effect.

\subsection{Grille}

The grille is an important auxiliary facility in sewage treatment facilities used to remove coarse suspended particulate matter in water. Its removal efficiency is related to the width of the gap. Later, the Moving Bed Biofilm Reactor (MBBR) Reactor is needed for biochemical treatment of wastewater, so a relatively fine grid is needed to remove larger particles and prevent the Biofilm on the filler from being destroyed [11].

\subsection{Regulating reservoir}

The regulating pool is an important facility for regulating the change of water quantity, especially for the facility with great change of inflow flow and weak impact resistance. For example, the wastewater of Huoshenshan Hospital comes from the areas with higher height and the areas with a lower height. Therefore, it is necessary to install this facility to regulate wastewater flow from different sources to protect the subsequent treatment facilities. For example, the low wastewater is subjected to pressure treatment to ensure its smooth and stable flow into the wastewater treatment system.

\subsection{Biochemical pool}

A biochemical pool uses biochemical principles to remove organic matter, nitrogen compounds, phosphorus compounds, and other pollutants in sewage facilities. MBBR process is generally used in hospitals treating patients with SARS-CoV-2. In Fig. 3, the MBBR biochemical pool in operation, which relies on the biofilm growing on the moving medium added to the reactor under the condition of oxygen to complete biodegradation, is shown in Fig. 4. The growth on the medium white filler is the biofilm. Biofilm contains different types of microorganisms, including aerobic, anaerobic, and facultative anaerobes, which can complete different biochemical processes and remove different pollutants. At the same time, its specific surface area is high, so it has a high water treatment efficiency [12]. The tank has a small volume, no need for aeration and flushing, and no need for packing support, which greatly saves construction time and operation cost and is very suitable for use in the case of public health emergencies. Therefore, after weighing, MBBR biochemical tank was selected as the treatment of medical wastewater which contains SARS-CoV-2.

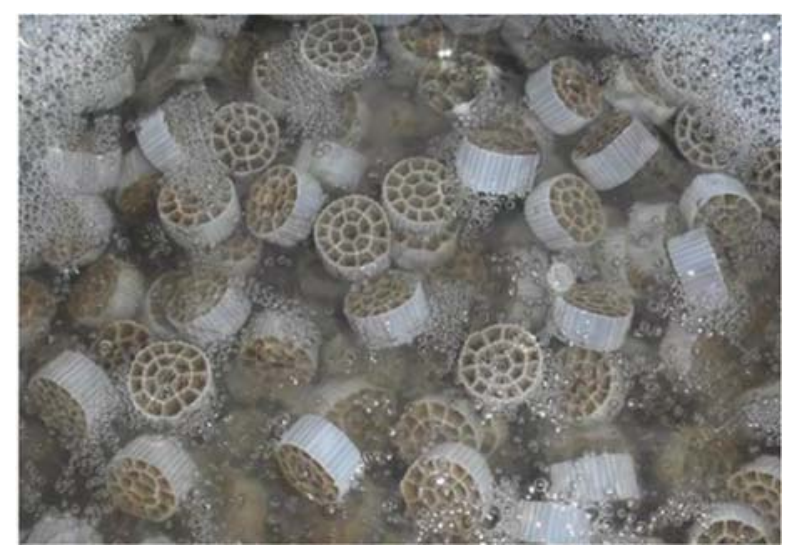

Fig. 3. MBBR biochemical pool in operation.

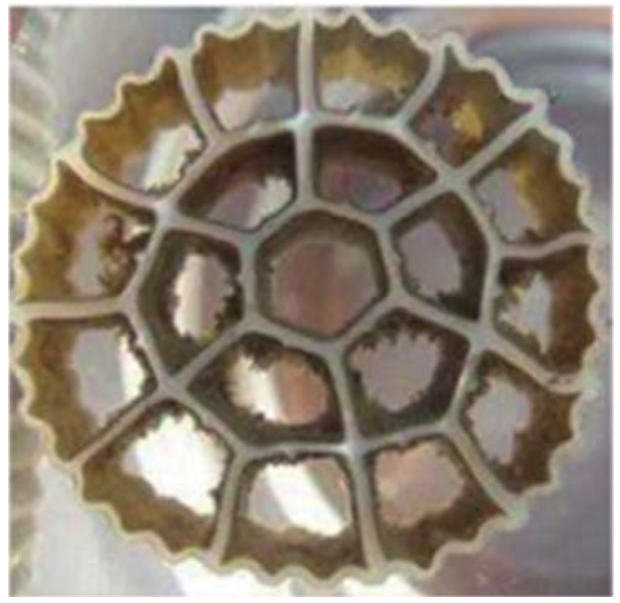

Fig. 4. Filler in MBBR biochemical pool.

\subsection{Clarifier}

The clarifier is the core structure of the conventional process of water plant treatment. It is used to separate the sewage from the particles in the water. By sedimentation, $80 \%$ to $90 \%$ of the particles in the water can be removed. Based on the traditional process, the removal methods of particulate matter in water have also developed new ways. These processes can greatly promote the treatment efficiency of medical wastewater, reduce the residence time of sewage in the facility, and reduce virus spiltration. To deal with the epidemic, flocculation inclined plate clarifier is a relatively high-quality choice, which is also the type of sedimentation tank selected by Huoshenshan Hospital. Inclined plate sedimentation tank is referred to between two pieces of the parallel plate forming shallow tank, is with particles in the precipitation of shallow water is separated. It uses the principle of "shallow layer settling", which can reduce the particle sedimentation 
distance, shorten the settling time, improve efficiency. The technology can also be combined with flocculation technology. People can add flocculant to sewage. The flocculant generated depends on the physical method to adsorb the pathogenic virus in water and separates it from sewage through precipitation to prevent incomplete disinfection. Its specific structure diagram and operation process are shown in Fig. 5.
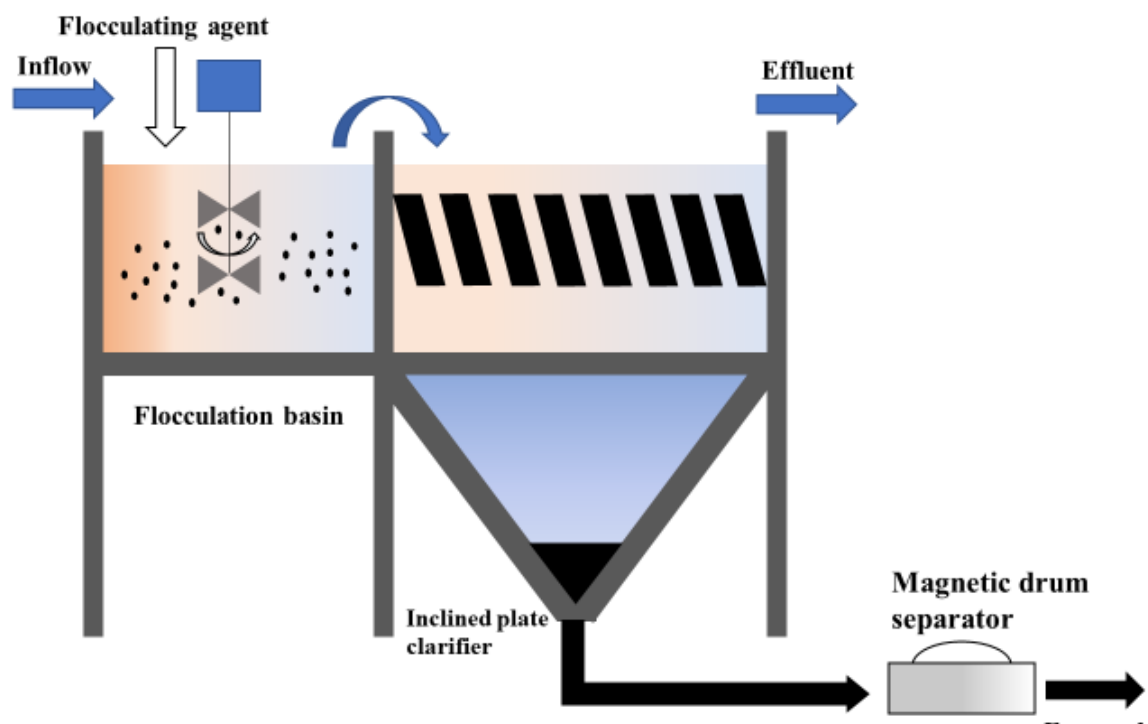

Excess sludge

Fig. 5. Flocculation inclined plate sedimentation tank.

\subsection{Disinfection technology}

Coronaviruses can be introduced into sewage through various sources, such as hand washing, sputum, vomiting [13], and primarily through viral shedding in the feces of infected individuals [14]. In addition, coronaviruses have been detected in urine samples from infected patients, such as SARS-CoV in 2003 [15], Middle East respiratory syndrome coronavirus in 2012 [16], SARS-CoV-2 in 2020 [17]. As a result, viruses can enter water bodies through multiple pathways and are discharged from hospitals along with the effluent. Suppose hospital wastewater is not disinfected and enters directly into the drainage system or river. In that case, it can transmit pathogenic microorganisms, viruses, antibiotic-resistant bacteria, drugs, and chemical contaminants, adversely affecting the environment and human health. Therefore, to eliminate the possibility of hospital wastewater becoming a transmission source, it is crucial to choose the appropriate disinfection technology to inactivate disease-causing microorganisms.

\subsubsection{Chlorine-containing disinfectants}

Chlorine-containing disinfectants mainly include bleaching powder, liquid chlorine, sodium hypochlorite, chlorine dioxide, etc. Most chlorine-containing disinfectants have strong oxidizing properties, effectively inactivating pathogens and having good hygienic effects [18]. The advantages and disadvantages of various chlorine-containing disinfectants are shown in Table 1.

Table 1. Comparison of Disinfection technologies for hospital wastewater [19].

\begin{tabular}{c|c|c|c}
\hline \multicolumn{2}{c|}{ Disinfection technology } & Advantages & Disadvantages \\
\cline { 2 - 4 } $\begin{array}{c}\text { Chlorine-containing } \\
\text { disinfectants }\end{array}$ & Liquid chlorine & Low energy consumption & $\begin{array}{c}\text { Inconvenient storage and } \\
\text { transport }\end{array}$ \\
\cline { 2 - 4 } & Sodium hypochlorite & $\begin{array}{c}\text { Low toxicity, simple equipment, stable } \\
\text { operation, easy control, and low } \\
\text { operation and preparation costs }\end{array}$ & $\begin{array}{c}\text { High energy consumption, } \\
\text { strong corrosiveness, and high } \\
\text { pollution }\end{array}$ \\
\hline \multicolumn{2}{c}{ Ozone } & $\begin{array}{c}\text { The ability of decoloring and } \\
\text { deodorizing and quick decomposition of } \\
\text { microorganisms }\end{array}$ & $\begin{array}{c}\text { High operation costs and } \\
\text { hazardous by-products }\end{array}$ \\
\hline
\end{tabular}

Liquid chlorine is one of the most commonly used disinfectants in hospital wastewater disinfection. Chlorine is a strong oxidizer and broad-spectrum bactericide that effectively kills bacteria and viruses in wastewater and has a continuous disinfection effect. Liquid chlorine disinfection has the advantages of easy availability of 
agents, low cost, simple process, mature technology, simple operation, accurate dosage, and does not require huge equipment. However, chlorine gas is toxic and highly corrosive, and its operation, management, and storage are hazardous to a certain extent. In a COVID-19 health emergency, when a septic tank is disinfected, the disinfection efficiency with chlorine is guaranteed by applying a dose higher than $6.5 \mathrm{mg} / \mathrm{L}$ and a contact time

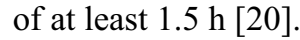

Chlorine dioxide is recognized as a highly effective disinfectant globally and has been used in China as a disinfectant for drinking water and hospital wastewater. In chlorination disinfection technology, chlorine dioxide has a strong oxidizing effect, does not produce organic chlorides, is simple and convenient to administer, is not affected by $\mathrm{pH}$, and has a broad-spectrum, highly effective disinfection effect. So chlorine dioxide disinfection technology has become the preferred method for hospital treatment that combines environmental and ecological benefits [18]. However, the disadvantage of chlorine dioxide is that it is inconvenient to store and transport and must be prepared on-site. The equipment should be placed in a ventilated place to prevent damage to the human respiratory system caused by improper operation of a small amount of chlorine dioxide escaping into the air. Wang et al. [21] found that SARS-CoV was completely inactivated by disinfection with chlorine at more than 10 $\mathrm{mg} / \mathrm{L}$ for $30 \mathrm{~min}$ after inoculation of $1 \mathrm{ml}$ of $10^{5} \mathrm{TCID}_{50}$ of SARS-CoV in $100 \mathrm{ml}$ of domestic sewage. However, under the same conditions, SARS-CoV could be completely inactivated only after $30 \mathrm{~min}$ of disinfection with $40 \mathrm{mg} / \mathrm{L}$ chlorine dioxide. So, Chlorine dioxide was less effective for the inactivation of SARS-CoV than chlorine.

Sodium hypochlorite disinfection uses sodium hypochlorite solution or on-site prepared sodium hypochlorite liquid as a disinfectant, and the hypochlorous acid produced after its dissolution has a good killing effect on pathogenic bacteria in the water, which can disinfect the sewage. Sodium hypochlorite has low toxicity, simple equipment operation, stable operation, easy control, low preparation cost, high energy consumption, high corrosiveness, and high pollution. Human-specific coronaviruses can last from 2 hours to 9 days on inanimate surfaces such as metal, glass, or plastic. Still, the survival time of the virus is shorter in environments above $30^{\circ} \mathrm{C}$. Therefore, as shown by data on coronaviruses, for viruses surviving on the surface of objects, $0.1 \%$ concentration of sodium hypochlorite can effectively inactivate them within 1 minute [22].

\subsubsection{Ozone disinfection}

Ozone is a disinfectant with a high bactericidal effect, with the capacity of decoloring and deodorizing [19], and is widely used in wastewater treatment projects. A schematic representation of the mentioned inactivation mechanisms for enveloped viruses is displayed in Fig. 6 [23]. The inactivation of viruses by ozone results from the reaction between ozone and the biomolecules that constitute the basic external and internal structure of the target organism.
Ozone can react with the nucleic acids of the viral genome after the molecules have diffused internally through the external structure. The external structure refers to the proteins and lipids of the viral envelope, such as the enveloped virus SARS-CoV-2. For SARS-CoV-2, ozone levels of approximately $0.1-0.4 \mathrm{mg} / \mathrm{L}$ in one minute can achieve about $4 \log _{10}$ of inactivation in aerosols [23]. The advantages and disadvantages of ozone are shown in Table 1. Ozone disinfection can decolorize and deodorize the treated wastewater. It is bright and transparent without odor. Although ozone disinfection can improve water quality and efficiency in a relatively short period, ozone preparation has high operating costs, produces byproducts that are harmful to human health, and excessive ozone can easily cause odor and secondary pollution. Therefore, ozone disinfection is mainly suitable for smallscale wastewater treatment systems, especially those with high effluent quality [19].

\section{Enveloped virus}

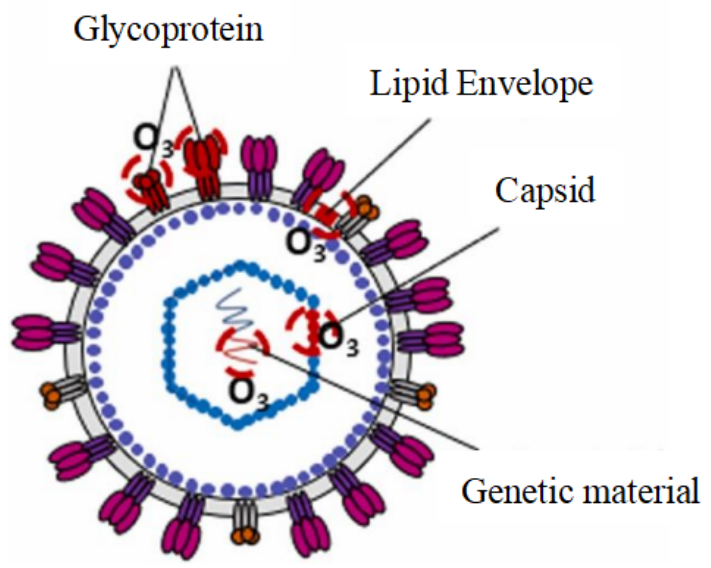

Fig. 6. Inactivation mechanisms of enveloped viruses by ozone [23].

\subsubsection{Ultraviolet light (UV) disinfection}

Ultraviolet light (UV) can be divided into 4 bands according to different wavelengths, including ultraviolet $\mathrm{A}$ (315 nm-400 nm), ultraviolet B (280 nm-315 nm), ultraviolet C (200 nm-280 nm), and vacuum ultraviolet (100 nm-200 nm). Of these, vacuum ultraviolet is absorbed by wastewater and cannot be used for disinfection. The energy band with wavelengths between $200 \mathrm{~nm}$ and $300 \mathrm{~nm}$ may damage the structure of DNA and RNA of bacteria, viruses, and single-celled microorganisms, thereby inhibiting protein synthesis. Therefore, ultraviolet $\mathrm{B}$ and ultraviolet $\mathrm{C}$ have the best germicidal effect [19]. Exposure of the virus to UV radiation causes cross-linking of nucleotides in the viral genome, leading to virus inactivation [24]. Studies have shown that DUV-LED inactivates SARS-CoV-2 efficiently and rapidly, with DUV-LED at $280 \pm 5 \mathrm{~nm}$ achieving $87.4 \%$ reduction in infectious virus titers within 1 second of UV irradiation and $99.9 \%$ reduction within 10 seconds [25].

The advantages and disadvantages of UV disinfection are shown in Table 1. UV disinfection has various 
advantages, such as short contact time for the disinfection process and no formation of any disinfection by-products, and low investment and operating costs. However, the penetration depth of UV radiation is not deep enough, and the occupational health risk is high.

\subsection{Sludge disposal}

After isolation of infectious SARS-CoV-2 from feces and urine of COVID-19 patients, the corresponding RNA was also detected from wastewater and sewage sludge [26]. In fact, enveloped viruses have been shown to survive in municipal wastewater systems for days to months. Sewage sludge, a byproduct of wastewater treatment plants, is also considered a reservoir for this novel coronavirus, as it enriches $30-50 \%$ of the pollutants in the effluent. The complex organic matter in the sludge protects the pathogenic virus from inactivation [27]. This suggests that novel coronaviruses can also be transmitted through sludge. Therefore, when carrying out medical wastewater treatment, attention should be paid to safe disposal methods for sludge promptly to avoid sludge staying in the storage tank for too long. Research findings indicate that the high-temperature anaerobic digestion of sludge and the multi-stage digestion processes have better-reducing effects on viruses. In response to the requirement of thorough sanitization of sludge, inactivating pathogens and viruses of sludge, using sludge disinfection combining with anaerobic digestion or high-temperature sanitization conduces to inactivate sludge pathogenic bacteria and viruses. Also, incineration is a suitable method of sludge disposal [28]. In the incineration treatment, the combustion temperature is usually maintained above $850^{\circ} \mathrm{C}$, and the residence time of the waste in the furnace is greater than 1 hour, ensuring the deactivation of SARSCoV-2 and achieving a safe sludge disposal solution [29]. The residual sludge from the sewage treatment of infectious disease hospitals is dewatered and packaged airtight and incinerated by incineration equipment, achieving the goal of the complete elimination of pathogenic bacteria [30].

\section{Recommendations}

\subsection{Reduce residual chlorine}

During the epidemic period, to ensure the effectiveness of medical wastewater treatment and prevent the spread of viruses, the treatment units enhanced disinfection, and most of the disinfection processes use chlorination disinfection, which led to an increase in the residual chlorine content of the influent water of the sewage treatment plant. In this case, the activity of activated sludge may be inhibited, which affects the efficiency of the biochemical treatment process. Chen L. et al. [31] found that sludge microorganisms' nitrification activity and denitrification activity were affected when highconcentration sodium hypochlorite was applied to activated sludge. In this regard, each treatment unit should strengthen the monitoring and management of the biochemical system and closely observe the condition of activated sludge. During the epidemic, it is also necessary to closely observe influent and effluent water quality and quantity changes and predict and adjust the process parameters to ensure that the system can operate stably. If the system has been affected by the high-concentration residual chlorine, it is necessary to consider adding ferrous iron to the adjustment tank to reduce it. The reaction products could enhance the coagulation process to maintain the stable structure of the floc and avoid the loss of nitrifying bacteria. What's more, it's also effective to add reducing agents such as sodium sulfite into the regulating pool, which can also reduce hypochlorite [32]. Relevant departments should also research the residual chlorine concentration of influent and effluent as soon as possible and introduce corresponding standard specifications for different types of residual chlorine. So, the future emergency treatment of medical wastewater can be justifiable and reasonable and reduce the impact of residual effluent chlorine on the water environment [33].

\subsection{Improve the degree of automation control}

As the sewage treatment work during the epidemic involves risks of virus infection, it is essential to boost the automatic management system. For example, the processing units can consider monitoring the flow rate, fecal coliform count, and other indicators to realize the automation operation of the selection and dosing of disinfectants, which will reduce the frequency of on-site work for workers. In addition, the inlets and outlets, agent dosing ports of each unit, or special equipment should be equipped with detection and emergency alarm measures to improve the efficiency of automated operation. So that the emergency plans can be launched timely when an accident occurs [34].

\subsection{Classify and treat medical wastewater reasonably}

According to the actual function, hospitals can be divided into general hospitals, specialized hospitals, infectious disease hospitals. The quality of wastewater produced by hospitals with different functions has significant differences, so it cannot be treated according to a uniform treatment process. Furthermore, when treating wastewater in hospitals, medical wastewater needs to be properly classified and treated according to quality. It's a must to strictly separate the sewage from hospital wards and nonward areas. The sewage and feces from infectious wards should be treated separately before being combined with other wastewater [35]. Rainwater needs to be collected entirely, and measures such as disinfection and physicochemical treatment before discharge shall be strictly enforced [36].

\subsection{Adjust the treatment plan in time}

During the epidemic, all sewage treatment units should optimize the disinfection process according to the treatment effect and costs to avoid affecting further 
treatment after the mixing of various up-to-standard wastewater. The disinfection method for different projects may not be limited to one single type. A combination of multiple disinfection processes is also available to reduce the dosage of disinfectant and the generation of disinfection by-products and reduce disinfection contact time. For instance, compared with the chlorine disinfection process, the ultraviolet disinfection process lacks the capacity for subsequent disinfection. It is recommended to construct temporary pipelines for dosing chlorinated disinfectants as an aid [36]. The "ozone + sodium hypochlorite" method is also practicable [37]. Ozone disinfection takes less time to kill pathogens and does not produce toxic or harmful by-products. In the process of processing, adding a small amount of sodium hypochlorite to control the residual chlorine in the water can provide the disinfection method with the continuous disinfection capability [37].

\subsection{Improve sealing of facilities}

To prevent the spread of viruses through aerosols, medical wastewater treatment facilities should be strictly sealed. In addition to capping all sewage and sludge structures, the waste gas should also be appropriately disinfected, such as ultraviolet disinfection, ozone disinfection, etc., to further prevent the spread of the virus. In addition, sealing checks regularly is also essential. People are more likely to contact drainage facilities than other processing facilities. Hence the processing units should also attach importance to the sealing of drainage facilities and pipelines and regularly check the sealing and blockage of sewers to prevent contaminating non-patient areas by backflow and groundwater pollution because of sewage leakage [35]

\section{Conclusion}

Under the influence of COVID-19, the content of the virus in medical wastewater has increased, and various treatment units have adjusted the treatment process correspondingly in response to the epidemic. For instance, reinforced septic tanks and fine grilles with smaller grids were used for wastewater treatment. Besides, MBBR and the flocculation slant plate process were widely used for biochemical treatment and sedimentation processes. It is crucial to increase the dosage of disinfectant since coronavirus can be introduced into water bodies through various sources and pose a threat to the environment and human health. In addition, safe disposal methods such as incineration are also needed for sludge, and it's proved that the disposal scheme of high-temperature anaerobic digestion and incineration can effectively inactivate sludge pathogens and viruses. Finally, the paper reflects on the existing treatment system for medical wastewater. It concludes by summaries and suggestions for specific treatment priorities and improvements for reference, such as paying attention to reduce residual chlorine, improving the degree of automation control, classifying and treating medical wastewater reasonably, adjusting the treatment plan in time, and improving the sealing of facilities.

\section{References}

1. C.C. Lai, T.P. Shih, W.C. Ko, H.J. Tang, P.R.J.I.J.o.A.A. Hsueh, Severe acute respiratory syndrome coronavirus 2 (SARS-CoV-2) and coronavirus disease-2019 (COVID-19): The epidemic and the challenges, 55(3) (2020) 105924.

2. M.L. Holshue, C. Debolt, S. Lindquist, K.H. Lofy, S.K.J.N.E.J.o.M. Pillai, First Case of 2019 Novel Coronavirus in the United States, 382(10) (2020) 929936.

3. B. Bja, B. Yza, C. Twa, A.J.J.o.E.C.E. Pk, Water science under the global epidemic of COVID-19: Bibliometric tracking on COVID-19 publication and further research needs - ScienceDirect, 9(4).

4. A. Bhatt, P. Arora, S.K.J.J.o.E.C.E. Prajapati, Occurrence, fates and potential treatment approaches for removal of viruses from wastewater: A review with emphasis on SARS-CoV-2, 8(5) (2020).

5. C. Rose, A. Parker, B. Jefferson, E. Cartmell, The Characterization of Feces and Urine: A Review of the Literature to Inform Advanced Treatment Technology, Critical Reviews in Environmental Science and Technology 45(17) (2015) 1827-1879.

6. Z. Dayi, Z. Xian, Y. Yunfeng, H. Xia, J. Jingkun, L. Miao, L. Haibo, L. Jing, L. Yi, L. Guanghe, L. Weiwei, Y. Chuan, Z. Ting, J. Yongzhong, X. Yan, H. Zhenyu, W. Xinzi, D. Songqiang, Q. Jiuhui, SARS-CoV-2 spillover into hospital outdoor environments \%J Journal of Hazardous Materials Letters, (prepublish) (2021).

7. R. Anil, A.L.J.P.T. Neera, Modified Septic Tank Treatment System, 24 (2016) 240-247.

8. S. Chong, T.K. Sen, A. Kayaalp, H.M.J.W.R. Ang, The performance enhancements of upflow anaerobic sludge blanket (UASB) reactors for domestic sludge treatment - A State-of-the-art review, 46(11) (2012) 3434-3470.

9. E.J. A., F.J. F., Solubilization of Particulate Organic Carbon during the Acid Phase of Anaerobic Digestion \% J Journal (Water Pollution Control Federation), 53(3) (1981).

10. A. Grobicki, D. Stuckey, Performance of the Anaerobic Baffled Reactor Under Steady-State and Shock Loading Conditions, Biotechnology and bioengineering 37 (1991) 344-55.

11. R. Costa, V.S. Souto, A. Prelhaz, L. Neto, D.B.J.W.S. Wolff, T.A.J.o.t.I.A.o.W.P. Research, Utilization of a hybrid sequencing batch reactor (HSBR) as a decentralized system of domestic wastewater treatment, 57(12) (2008) 1951.

12. S. Latif, A. Rajpal, A.A.J.J.o.W.P.E. Kazmi, Upgradation of conventional MBBR into Aerobic/Anoxic/Aerobic configuration: A case study of carbon and nitrogen removal based sewage treatment plant, 40(April 2021) (2021) 101921.

13. B. Adelodun, F.O. Ajibade, R.G. Ibrahim, H.O. Bakare, K.S.J.S.o.T.T.E. Choi, Snowballing transmission of COVID-19 (SARS-CoV-2) through 
wastewater: Any sustainable preventive measures to curtail the scourge in low-income countries?, 742 (2020) 140680.

14. X.S. Wei, X. Wang, Y.R. Niu, L.L. Ye, Q.J.C.G. Zhou, Hepatology, Diarrhea is associated with prolonged symptoms and viral carriage in COVID-19, 18(8) (2020).

15. D. Xu, Z. Zhang, L. Jin, F. Chu, Y. Mao, H. Wang, M. Liu, M. Wang, L. Zhang, G.F.J.E.J.o.C.M. Gao, I. Diseases, Persistent shedding of viable SARS-CoV in urine and stool of SARS patients during the convalescent phase, 24(3) (2005) 165-171.

16. Clinical features and virological analysis of a case of Middle East respiratory syndrome coronavirus infection \%J Lancet Infectious Diseases, 13(9) (2013) 745-751.

17. H. Nomoto, M. Ishikane, D. Katagiri, N. Kinoshita, N.J.A.J.o.I.C. Ohmagari, Cautious handling of urine from moderate to severe COVID-19 patients, 48(8) (2020).

18. M.A. Yu-Mei, W. Zhao, L.J.O. Hong-Yan, Health, Application Progress of Hospital Wastewater Treatment Methods, (2010).

19. J. Wang, J. Shen, D. Ye, X. Yan, Y. Zhang, W. Yang, X. Li, J. Wang, L. Zhang, L. Pan, Disinfection technology of hospital wastes and wastewater: Suggestions for disinfection strategy during coronavirus Disease 2019 (COVID-19) pandemic in China, Environmental Pollution 262 (2020) 114665.

20. A. Gv, B. Vg, C. Cg, C. Go, C. Ac, C. Za, D.J.C.S.i.C. Lfdp, E. Engineering, Considerations on water quality and the use of chlorine in times of SARS-CoV-2 (COVID-19) pandemic in the community, 2 (2020).

21. X.W. Wang, J.S. Li, M. Jin, B. Zhen, Q.X. Kong, N. Song, W.J. Xiao, J. Yin, W. Wei, G.J.J.J.o.V.M. Wang, Study on the resistance of severe acute respiratory syndrome-associated coronavirus, 126(1-2) (2005) 171-177.

22. A. Gk, B. Dt, B. Sp, B.J.J.o.H.I. Es, Persistence of coronaviruses on inanimate surfaces and their inactivation with biocidal agents, 104(3) (2020) 246251.

23. B. Bayarri, A. Cruz-Alcalde, N. López-Vinent, M.M. Micó, C. Sans, Can ozone inactivate SARS-CoV-2? A review of mechanisms and performance on viruses, Journal of Hazardous Materials 415 (2021) 125658.

24. S. Young, J. Torrey, V. Bachmann, T. Kohn, Relationship Between Inactivation and Genome Damage of Human Enteroviruses Upon Treatment by UV254, Free Chlorine, and Ozone, Food and Environmental Virology 12(1) (2020) 20-27.

25. H. Inagaki, A. Saito, H. Sugiyama, T. Okabayashi, S.J.E.M. Fujimoto, Infections, Rapid inactivation of SARS-CoV-2 with deep-UV LED irradiation, (2020) 1-8.

26. W. Randazzo, P. Truchado, E. Cuevas-Ferrando, P. Simón, A. Allende, G. Sánchez, SARS-CoV-2 RNA in wastewater anticipated COVID-19 occurrence in a low prevalence area, Water Research 181 (2020) 115942.

27. W. Yang, C. Cai, X. Dai, The potential exposure and transmission risk of SARS-CoV-2 through sludge treatment and disposal, Resources, Conservation and Recycling 162 (2020) 105043.

28. S. Ducoli, A. Zacco, E. Bontempi, Incineration of sewage sludge and recovery of residue ash as building material: A valuable option as a consequence of the COVID-19 pandemic, Journal of Environmental Management 282 (2021) 111966.

29. F. Di Maria, G. Bidini, M. Lasagni, A. Boncompagni, On time measurement of the efficiency of a waste-toenergy plant and evaluation of the associated uncertainty, Applied Thermal Engineering 129 (2018) 338-344.

30. M. Hua, W. Huang, Sewage treatment device of infectious disease hospital comprises sewage treatment system, excess sludge treatment system and waste gas treatment system, and the sewage treatment system composed of ozone pre-disinfection tank and grille, Anhui Lvheng Environmental Protection.

31. R.Q. Wang, Y. Wang, L.W.J.C.W. Yuan, Wastewater, Influence of High-concentration Disinfectant on Microorganisms in Biofilm Formed in Reclaimed Water Pipeline, (2016).

32. L.I. Zhi-hua, G.A.O. Xing-dong, H. Zhen-yu, M.A. Zhi-bo, Effect of Chlorine Disinfectant on Activated Sludge and Its Countermeasures, 36(6) (2020) 28-32.

33. X.I.A. Meng, S.U. Yiming, C. Jiabin, Z. Xuefei, Z. Yalei, Effect of sewage treatment technology on virus removal and emergency treatment technology in epidemic period. Environmental Pollution and Control, 42(4) (2020) 514-518.

34. P. Hongbo, Research on hydrolysis acidification + filtration + disinfection process for treating hospital wastewater. Liaoning Urban and Rural Environmental Science \& Technology, 38(9) (2018) 32-34.

35. W.E.N. Jianxin, S.U.N. Jie, L.I. Jia, Current situation and suggestions on medical sewage treatment in 2019-nCoV epidemic-stricken area. Journal of SouthCentral University for Nationalities(Natural Science Edition), 39(2) (2020) 118-122.

36. D. Xu, Z. Yu, S. Xin, L.I. Fengmin, New Technology and Future Demand for Medical Wastewater Treatment. Technology of Water Treatment, 46(9) (2020) 1-6,29.

37. L.I. Rong, Y.U. Zhong-xun, Application of "Ozone + Sodium Hypochlorite" in Water Disinfection in Industrial Enterprises. Environmental Science Survey., 38(5) (2019) 71-74. 